\title{
How Technology Drives the History of the Green Revolution
}

\section{Gregory Morgan Swer}

To cite this article: Gregory Morgan Swer (2020): How Technology Drives the History of the Green Revolution, Capitalism Nature Socialism, DOI: 10.1080/10455752.2020.1862889

To link to this article: https://doi.org/10.1080/10455752.2020.1862889

册 Published online: 22 Dec 2020.

Submit your article to this journal

Q View related articles $\widetilde{ }$

View Crossmark data \lceil 


\title{
How Technology Drives the History of the Green Revolution
}

\author{
Gregory Morgan Swer
}

Department of Social Sciences, Walter Sisulu University, Mthatha, South Africa

\begin{abstract}
This paper argues that histories of the Green Revolution are often underpinned by commitments to theoretical models of technology and science in ways which shape the parameters of such narratives in politically normative ways. This paper explores the accounts of the Green Revolution in India given by Vandana Shiva and Govindan Parayil and demonstrates the ways in which these accounts are influenced by their models of technology and science. It is argued that Shiva and Parayil represent key theoretical positions in technological theory, determinist and instrumentalist, respectively, and that examination of their Green Revolution narratives clearly indicates the ways in which such theoretical commitments can determine the scope and content of analyses of technology-driven development, and thereby exclude political content necessary for the evaluation of the efficacy of such development and the validity of the theoretical model.
\end{abstract}

ARTICLE HISTORY Received 15 January 2019; Accepted 23 October 2020

KEYWORDS Green Revolution; Vandana Shiva; Govindan Parayil; technological determinism; instrumentalism

\section{Introduction}

The purpose of this paper is to use the history of the Green Revolution in India to examine the ways in which technological narratives underpin and determine the interpretation of case studies in the field of development. It will be argued that these technological narratives can be usefully identified as belonging to either instrumentalist or determinist camps. To demonstrate this point I have selected two commentators on the Green Revolution, Vandana Shiva and Govindan Parayil, whose work is well known to people working in the fields of development and development studies, and whose analyses align with determinist and instrumentalist positions, respectively. ${ }^{1}$ I argue, using the work of Shiva and Parayil, that the selection of one

\section{CONTACT Gregory Morgan Swer gregswer@gmail.com}

${ }^{1} A$ clarificatory point on the use of the terms instrumentalism and determinism in this context. Technological determinism tends to be conflated in the popular imagination with what Reinfelder (1980) terms the technicist position, the belief that technology is the major driver of societal change and 
of these technological models shapes the type of development narrative constructed.

The significance of the influence of technological models upon development narratives is twofold. Firstly, the technological model adopted alters the parameters for what constitutes a relevant factor in the analysis and evaluation of technological interventions in development contexts - with factors deemed irrelevant becoming invisible - and thereby the criteria for the assessment of that intervention's success or failure. Secondly, the distinction between instrumentalist and determinist positions hinges upon a distinction between fact and values.

By portraying technology as value-neutral instruments of human volition, and value considerations as external to the technological artefacts themselves, instrumentalism effectively places the design and selection of such artefacts beyond political critique, and thereby renders opaque the role played in these processes by the interests of those who wield economic power.

The wider significance of this analysis is that the determinist and instrumentalist positions are present not solely in the retrospective analysis of past developmental episodes, but in the projective planning of future interventions. And insofar as instrumentalist accounts dominate both developmental and technological analysis, the instrumentalist interpretation of past development case studies serves as both guide to future endeavours and validation of the continued application of the values and criteria they embody. I suggest that if meaningful development is to occur - that is to say, context-sensitive development that serves the requirements of those directly affected by it then the technological assumptions that underpin development analyses and planning must be made visible and subjected to ideological critique. I conclude the paper by suggesting that whilst aspects of Shiva's history of the Green Revolution may be problematic, the narrative put forward nonetheless provides criteria that should serve to guide both retrospective development analyses and prospective planning.

\section{Shiva's Philosophy of Science and Technology}

I argue that understanding Shiva's model of science and technology is essential to understanding her characterisation both of the Green Revolution and

has its own teleology. In practice, however, most advocates of a determinist position hold that technology has the power to shape rather than determine societal development, and either reject, or severely qualify, the idea that technology has its own autonomous course of development (Swer 2014). And instrumentalism, as a position in technological analysis, is often held to have been superseded by social constructionist approaches that explore the design process of technological artefacts (see McCarthy 2017). I argue, however, that social constructivism is itself a form of instrumentalism in that it too views technology as inherently value-neutral and pays little heed to the application of that technology or the materiality of engagement with it. 
the role that technology played in it. ${ }^{2}$ The reason that Shiva's views on the nature of modern science are relevant to a discussion of the technology of the Green Revolution is that she comprehensively rejects the notion that any meaningful distinction can be made between science and technology. Now, rather than this being merely a repetition of the familiar notion that science is just theory, and technology the application of that theory, Shiva argues that the business of science is, amongst other things, the production of technology (Shiva 1988, 237). Dismissing the idea that the character of science is academic, rather than industrial, and geared towards pure research, whilst technology is the development of scientific theory for the purposes of practical application and commercial exploitation, Shiva points to a nexus between the mode of knowledge that modern science represents and the economic interests of modern industrial capitalism. Modern science provides a naturalised ideology for capitalist economics which both legitimates it and provides it with its means of development (Bridgstock 1998, 36; Shiva 1988, 234). According to Shiva, the ideology of science is what she terms reductionism and technology represents the point at which this ideology overlaps with industrial capitalism.

As a consequence of this partnership between economic interests and modern science, Shiva asserts that science cannot credibly claim to be separate from society and politics at either a theoretical or practical level. By operating a reductionist epistemology and ontology, technocratic science legitimates its own cognitive superiority in social and political matters, whilst simultaneously absolving itself of any of the responsibility for any negative social and political consequences of the "technological fixes" that it explicitly offers (Shiva 1991, 21). For Shiva, the production of scientific knowledge and its utilisation are not separate processes. Science, on her account, consciously produces technology for socio-political ends. She states that "the dominant stream of modern science, the reductionist or mechanical paradigm, is a particular response of a particular group of people," namely Western capitalist patriarchy (Shiva 1989, 15). Science depicts the world and its processes in such a way as to "open up areas for exploitation and invasion" (Shiva 1993,129). And having depicted reality in such a way as to invite capitalist exploitation, science provides the technological tools to effect such exploitation. Indeed, science's continuing ability to produce technologies of this sort is one of the reasons for the generally uncritical acceptance of its claims to epistemological superiority. Thus, as both the

\footnotetext{
${ }^{2}$ The Green Revolution narratives given in the following sections are those of Parayil (sections 4 and 5) and Shiva (sections 2 and 3). They are intended to exemplify the ways in which their historical narratives are shaped by their concepts of technology. I take no position on the truth of their individual historical claims or the veracity of their historical accounts, and merely recount their technological positions and the key features of their technological Green Revolution narratives. Thus any pronouncements made in these sections should be taken to represent the views of Parayil or Shiva only.
} 
ideology and tool of capitalist exploitation, science is responsible for the social repercussions of its technologies.

According to Shiva, modern science, both as knowledge and practice, perpetrates violence both indirectly and directly against society and nature. Here Shiva's views on technology and science intersect with her ecological metaphysics, according to which the properties manifested by any element of a system under study are determined by the relationships which are taken to define the context of study (Shiva 1988, 234; Swer 2020). Thus, the selection of the context determines the properties perceived in nature, and the selection of the context is itself determined by the values and priorities guiding the perception of nature, in the case of modern science these determining values being reductionist. The reductionist ontological assumption that the basic processes of a system are mechanical, and that all systems are reducible to their constituent parts which are discrete and atomistic is thereby a misrepresentation of nature, as it ignores the fact that a system is more than just the sum of its parts. By isolating aspects of nature from their natural relationships and surroundings in its studies and theorisations, modern science presents a distorted model of nature.

This ontological distortion results in certain reductionist epistemological assumptions, namely that knowledge of the parts of a system gives knowledge of the whole, and that experts are the only legitimate seekers and justifiers of knowledge. It is this combination of ontological and epistemological assumptions that Shiva identifies as the main cause of much of the social violence and ecological destruction that we see today. Interventions in nature in the form of technology do harm due to the producers and utilisers' ignorance of the natural system. The privileging of scientific knowledge, method and knowers not only prevents the study of the other properties of nature by denying the epistemological legitimacy of other modes of knowledge, but also transforms that majority of the populace who hold that knowledge into "non-knowers" through the creation of the expert/non-expert dichotomy, even in areas of praxis in which the majority regularly operate (Shiva 1989, 97; Swer 2019, 256-257). Thus, modern reductionist science carries out violence against humanity at an epistemological level by removing its cognitive authority, and it also carries out physical violence against nature. It is the combination of this cognitive alienation and the material consequences of this natural violation that result in the rise of social violence and unrest (Shiva 1988, 232-233). ${ }^{3}$

\footnotetext{
${ }^{3}$ Shiva does at times write as if these exploitative features were necessary features of modern western technology. I suspect that she is being hyperbolic in these instances, as opposed to making an essentialising claim about all modern Western technology sub specie aeternitatis. Of course, this defence in turn raises questions about which Western technologies can be held to have deterministic properties and what it is that differentiates them from other, non-deterministic, Western technologies. And whether it is only modern Western technoscience that has these deterministic capacities or whether the technologies/sciences of other times and cultures have such capacities as well. Such
} 


\section{Shiva's Account of the Green Revolution}

An awareness of Shiva's views on the nature of science and technology enables us to better understand the form that her Green Revolution account takes. Shiva portrays the Green Revolution in India as a failure in its conception, inception and consequences. Pointing to the global political context at the time of the Green Revolution (i.e. the Cold War), Shiva argues that the scientific movement which developed the High Yield Variety (HYV) technology and which agitated for its adoption throughout Asia, Africa and Latin America, was not motivated by a desire to alleviate poverty and food scarcity in less developed countries as an end in itself. Rather, it viewed this as the most effective means of suppressing the spread of communism through those countries (Shiva 1991, 14). So, regardless of the Indian government's motivations in adopting and applying HYV technology, the very point of the existence of the technology was to serve a political purpose: namely, to use the HYV technology to surpass nature, thereby creating conditions of material abundance which would not support communist insurgency. As Shiva puts it, "the Science and Technology of the Green Revolution were an integral part of socio-political strategy aimed at pacifying the rural areas of developing nations in Asia" (Shiva 1991, 52). In other words, HYV technology was intended to alter political relations in nations deemed by the Western powers to be at risk.

In addition, the maintenance of these conditions of material abundance would necessitate the continued provision of Western inputs, namely chemical inputs. Shiva characterises the technological dimension of the Green Revolution as a "seed-fertiliser" package, due to the fact that the new HYV had been bred to be high consumers of fertiliser (usually 3-4 times higher than traditional varieties). In addition to Western Cold War interests being served by India's Green Revolution, Shiva also points to the commercial interests being advanced. By the end of the Second World War, Shiva argues, there was an excess of fertiliser in the industrialised nations, and American chemical manufacturers sought to increase overseas fertiliser consumption to recoup their investments. According to Shiva, the spread of the HYV seed technology is intimately connected with this push to expand the American petro-chemical market, due to the fact that wherever the new seeds were adopted, a market for chemical fertilisers would appear (Shiva 1991, 104-105).

On Shiva's account, the main selling point of the HYV technology to the Indian government was its supposed ability to produce material abundance

questions are perennial issues in the Philosophy of Technology and whilst I do not doubt that a justification of Shiva's position could be constructed, it is the case that Shiva does not attempt to provide one. Consequently, her version of technological determinism verges on the monolithic and ahistorical. In this regard, Shiva's account might well benefit from engagement with more dialectical determinist accounts with a broader historical scope, such as those of Lewis Mumford $(1934,1967)$ or Herbert Marcuse (1964). 
using scientific knowledge to exceed the limits of nature. Shiva categorically denies that it did so. The adoption of the American chemical agricultural paradigm encouraged Indian scientists, government officials and farmers to believe that chemical fertilisers were superior substitutes for the natural organic fertility of the soils. Despite initial bumper harvests, Indian farmers soon faced diminishing returns on their chemical investment. Dwarf HYVs have a considerably higher nutrient intake than traditional varieties and return far less organic matter to the soil, thereby disrupting the nutrient cycle and causing micronutrient deficiencies in the soil. The widespread shift from pulses and coarse grains to monoculture wheat and rice farming has exacerbated this process, wheat and rice being soil-depleting crops. Shiva attributes the land-degrading rather than land-augmenting effects of Green Revolution technology to the reductionist scientific paradigm behind it, which was incapable of recognising that "plants need more than NPK (nitrogen, phosphorous, potassium) for growth" (Shiva 1991, 112), and viewed traditional sustainable agriculture within ecological limits as "primitive" agriculture which under-utilised land.

In addition to the need for chemical inputs, the HYV technology of the Green Revolution also requires intensive irrigation. Due to adoption of HYVs and the movement towards wheat and rice monocultures, types of plant requiring intensive water inputs, the demand for water increased dramatically. The construction of dams and new irrigation channels to provide the necessary water supply has had significant ecological consequences. Taking Punjab and Haryana as case studies, two of the Indian states whose climatic conditions were deemed "well-suited" to the needs of the Mexican HYV wheat (Byres, Crow, and Ho 1983, 33), Shiva argues that the changes in irrigation methods necessitated by the adoption of HYV technology and agricultural methods has resulted in further land-degradation. The new water intensive cultivation patterns have added more water to the ecosystem than can be accommodated by the system's drainage potential. This has brought about a rise in the water table which, due to the high level of salt deposits in the region, has resulted in the "desertification" of large tracts of farmland through waterlogging and salination (Shiva 1991, 128-129). At the social level, the traditional reciprocal system of water rights has been disrupted by the centralisation of power in the hands of the central government which controls the dams and the irrigation systems. This disempowerment of the agrarian populace combined with the commercialisation of water rights and other agricultural inputs has resulted in social unrest and acts of violence, both against the central government, and against other classes and castes. The possibility of further and greater violence increases as the HYV yields continue to fall.

In summary, Shiva's analysis of the Green Revolution concludes that the HYV technology was the instrument of a Western socio-political agenda, a 
"technological fix," and was designed as such. The reductionist ideology which lay behind the construction of the technology has resulted in severe ecological damage due to its mechanistic/atomistic view of natural processes. In addition to failing as an agricultural strategy, the Green Revolution also failed as a political strategy. The effective "de-skilling" of the peasant farmer through the imposition of a new agricultural model, and the reduction of traditional communal rights and responsibilities into commercial interactions between individuals, has resulted in considerable social disruption, rather than social pacification through economic growth.

Shiva's technological determinist perspective leads her to expect that capitalist interests will be in operation, overtly and/or covertly, in the technology transfer of HYVs to Indian agriculture in the Green Revolution. Shiva holds that technology is never value-neutral, that it originates within a particular socio-economic matrix and is consequently both a reflection and a carrier of the interests of the ruling elite of its place of conception and creation. Thus, the transfer of a technology designed within a socio-economic system committed to the maintenance and extension of systems of exploitation is likely to create or reinforce similar systems of exploitation in its host society. In this way, Shiva's conception of technology goes beyond an understanding of technology as artefact, or system of technological rules for its operation, and incorporates as a matter of course class, gender, and ecological dimensions. As a result, evaluation of the efficacy of any technological application automatically includes within its analytic framework the impacts of that technology on class, gender, and ecological relations in the host society. This, as we shall see with Parayil, is not the case with all theoretical frameworks for technological analysis.

\section{Parayil's Philosophy of Technology}

Parayil, occupying a liberal, technocratic position, argues that technology is essentially a form of knowledge and that occasions of technological change, like the Green Revolution, are the outcome of what he calls problem-solving activity (Parayil 1991c, 235). On the subject of whether a meaningful distinction can be made between science and technology, Parayil asserts that technology is intellectually and epistemologically autonomous from science as a knowledge system. He explicitly rejects the positivist position on the relationship between science and technology which presents technology simply as applied science. Parayil concedes that the two disciplines are connected but portrays the relationship as an interactive one between distinct disciplines (Parayil 1991a, 290). ${ }^{4}$

\footnotetext{
${ }^{4}$ Parayil uses the term "interactive" interchangeably with the term "dialectic" in describing the relation-
} ship between science and technology, and between the various components involved in the 
Aside from its dismissal of technology's cognitive independence, Parayil's main objection to the received view is that it perceives the artefactual dimension of technology to be its essential characteristic. For Parayil, technology is knowledge. Technological techniques and artefacts are products of that knowledge. Whilst the epistemic focus of science is "knowing," the epistemic focus of technology is "doing" and most importantly "solving" (Parayil 1991b, 36). Also, whilst scientific knowledge changes through paradigmshifts which may involve conceptual and epistemological ruptures in which some aspects of knowledge are lost, technology as knowledge is evolutionary and cumulative. Technology develops in response to changes in the world around it through continuously improving antecedent technological knowledge (Parayil 1991c, 241). On the subject of the social construction of knowledge, Parayil sees it as something of a non-issue. Unlike science which seeks to provide knowledge of nature, technology's purpose is to function almost entirely within the social sphere. Technology exists to provide solutions to social problems, be it a desire for greater efficiency in activity or lower costs. The existence of a social problem results in the construction of an environment in which technological development to resolve the problem may take place. Those who determine the environment are particular groups within society, who are inevitably motivated by political, cultural, or economic interests or concerns. Thus, any technological change that results is inevitably socially constructed (Parayil 1991c, 242).

According to Parayil, technological change can be characterised as the interplay and combined effect of a number of technological activities:

- invention

- innovation

- development

- transfer

- diffusion.

There is no hierarchy to these activities, nor a chronological sequence (Parayil 1991a, 295; Parayil 1997, 171-172). Rather, they operate in an "interactive-dialectic" following the evolutionary trend of technological knowledge. As these factors interact, they give rise to what Parayil calls a "technological algorithm - "a heuristic which facilitates decisions regarding the best means for transforming the new technological knowledge into material outputs and artefacts (Parayil 1991a, 297). The success or failure of technological transfer, be it imported or newly created technological knowledge, ultimately depends not on the actors posing the social problem that the new technology is intended to address and creating the development

development and application of technology. "Dialectical," for Parayil, has no deliberate Hegelian connotations, and instead refers to a dialogic process between parties involved in the development and/or application of technology that is governed by rational considerations. 
environment to do so, but on the acceptance and adoption of the new technology by its intended recipients: those who will have to apply the new technology (Parayil 1991b, 41). This acceptance is brought about partly through use of the technological algorithm, and partly through a dialectic between the producers of the technology and the recipients, in which the recipients' feedback further determines the nature of the technology eventually accepted. This recipient/producer dialectic is the key to successful technological transfer and takes the form of a trial and error learning process, or, as Parayil calls it, a "selective-retention process," which guides the evolution of technological knowledge (Parayil 1991c, 240-241).

\section{Parayil's Account of the Green Revolution}

By Parayil's reckoning, the Green Revolution is clear example of "relatively successful technology transfer" and technological change (Parayil 1992, 737). The key to understanding the nature of the technological change in the Green Revolution, for Parayil, lies not in the transferred HYV seeds, nor their chemical inputs, but in the knowledge which lay behind their development, use and acceptance.

The technology change of the Green Revolution (which for Parayil is what was "revolutionary" about it) was necessitated by the crisis in Indian food production which was exemplified by the shortages between 1965 and 1967. These shortages were the result of the Indian government's failed development policies which, being based on the Soviet Union's centrally planned economic model, favoured rapid industrialisation at the expense of the agricultural development (Parayil 1992, 753). The Indian government required a means of achieving self-sufficiency in food production, and yet could not achieve this goal through extension of agriculture due to the absence of suitable land. This was the social problem that technology was required to address: the provision of a means of increasing national agricultural output by increasing the productivity of the land.

The actual problem-solving technological process took place in stages. The initial stage involved construction of a national agricultural research system and reform of the governmental agricultural bureaucracy to facilitate the transfer and application of HYV technology to India. By 1962 HYV Mexican wheat had been successfully tested, and by 1964 so had HYV rice. In the second stage, the government initiated a nation-wide propaganda campaign to extol the virtues of the new technology and carried out villagelevel demonstrations of the new technology's efficacy. In this way the peasant farmer learned the new technological knowledge from the experts' propagating it, and then chose to apply it themselves, resulting in mass demand for the "miracle" seeds and the consequent importation of 18,000 tons of HYV wheat from Mexico, "the largest seed transfer in human history." 
Following the widescale adoption of HYVs, the increase in national wheat yield doubled annually between 1970 and 1974 and India became selfsufficient in food grain production (Parayil 1991b, 40).

For Parayil, what is significant here is how development of the technology (its invention, innovation, and development) interacts with the diffusion of the technology (its transfer and adoption) to bring about change. Through the instruction of the experts and trial and error, the peasant farmer came into possession of the new technology (as knowledge), albeit knowledge altered by the technological algorithm into a simplified form that the farmers could absorb and apply. It was only then that the HYV technology as artefact and technique became significant to the farmer, once they had, in effect, been given cognitive authority over them. And part of the process of this establishment of cognitive authority, was the provision of feedback from the farmer to the expert which resulted in the modification of the technology as artefact and technique. It was because of this epistemological change that the HYV technology was adopted and successfully transferred.

Not only did the technology change give India self-sufficiency; it also liberated the peasant. Prior to the Green Revolution peasant farmers had obtained necessary inputs through commodity exchange, due to the nonexistence of markets. Post-Green Revolution the peasant's way of life was permanently altered within decades. Now they are tied into a commercial system of agriculture, where agriculture is "a calling beyond mere subsistence," and they can receive wages for their labours. The need to gain credits for seed and other input purchase forces them to enter the market (Parayil 1992, 753). In effect, wherever the Green Revolution has taken hold, material conditions have invariably improved through a trickledown effect.

\section{Issues Regarding the Conceptualisations of Green Revolution Technology}

Clearly, Parayil and Shiva's models of technology and technological change disagree significantly, but what is also of interest are the ways in which they concur. For example, both agree that technology and technological change are social in nature, and that social interests play a part in the shaping of technology. And both seem to agree that in the Green Revolution, the source of the technological change is best understood through the analysis of "technology as knowledge." However, here the similarity ends. For Shiva, the study of technology as a mode of knowledge is significant only because its reductionist character forces one to acknowledge the political character of modern science; whereas for Parayil, who asserts technology's autonomy from science, the study of technology as a mode of knowledge is significant because it is the epistemological aspect of technology that 
effects technological change. This difference of focus, I argue, ultimately stems from their different stances on the fact/value distinction with regards to technology, which in turn has significant consequences for their positions on technological issues.

Tiles and Oberdiek (1995) argue that at the base of the instrumentalist account of technology is the assertion that technological artefacts constitute natural objects, and are therefore neutral with regards to human intentions. ${ }^{5}$ By defining technology operationally, as material or conceptual tools, instrumentalists believe that they are offering an empirically meaningful account of the nature of technology that in itself requires no further explanation, and thus technology can be treated as a natural object. Elsewhere I summarise the instrumentalist position thus, "Things belonging to the natural world are held to be facts, and thereby value-neutral. By treating technology as a natural object, it becomes a fact, and it too is held to be value-neutral" (Swer 2014, 204). Any ethically or socially problematic issues arising from the operations of technology are placed firmly on the value-side of the fact/value dichotomy. Thus, what we do with technology can be subject to political critique, but technology itself (including its conception, design, and operations) is placed beyond such critique. On an instrumental account, such as Parayil's, technology's presumed status as a natural object makes it axiomatic in technological analysis that technology itself, as a value-neutral tool or as body of factual knowledge, is above politics. And this conceptual presumption has clear implications for the scope of Parayil's subsequent analysis of the Green Revolution.

For example, Parayil portrays the material manifestations of technology as the effects of developments in technological knowledge; not exactly epiphenomena, but certainly of secondary importance in understanding change. Thus, if technological artefacts are of any genuine significance in understanding the nature of the Green Revolution, it is only at the level of the artefact's knowledge content (Parayil 1991a, 299). That is, the knowledge to understand the artefact's workings and to adapt or reproduce them. However, as Shiva would doubtless point out, this view of the artefactual aspects of technology overlooks any possible independence that the artefacts may develop. Parayil operates under the assumption that technology as artefact is nothing more than physical objects constructed by humanity. As he puts it, "artifacts are only the physical realisation of technical knowledge" (Parayil 1991b, 46). Unlike nature, which has a source of motion in itself, artefacts have a tendency to deteriorate because, as Mitcham puts it, their form and matter are not really one (Mitcham 1994, 172). Thus, according

\footnotetext{
${ }^{5}$ Tiles and Oberdiek $(1995,47)$ note the contradiction involved in considering something that owes its form and existence to human design, i.e., was brought into existence for a particular purpose, as a natural object.
} 
to Parayil, technology as knowledge is the appropriate focus for technological change in the Green Revolution because if the recipient of the technology did not have the requisite technological knowledge, and thereby the power to shape the artefacts to their own ends, then the transferred technology would have become extinct as the artefacts were used up or worn out (Parayil 1991b, 41). Now, whilst one might concede this point with regards to mechanical artefacts, like tractors or pumps for tubewells, it is by no means certain that one can apply this kind of definition to biotechnology, where form and matter do indeed seem to be as one (Mitcham 1994, 174). In so far as the HYV artefacts can operate independently of human control, it may be argued that they be granted ontological as well as epistemological status. Shiva certainly occupies this position, arguing that whilst the epistemological content of HYV artefacts may be pre-determined, the seeds themselves exhibit a degree of autonomy.

In addition to the autonomous properties of artefacts, we might also consider the question concerning the nature of technology's social construction and its bearing on the question of whether the Green Revolution was a technological fix. What is meant here by the statement that technology is a social construction? For Parayil, as we have seen, this amounts to that recognition that technology serves human purposes, and that the tasks that it is set are framed by actors with their own political and economic agendas. However, despite the social contingency of technological knowledge, Parayil believes that by analysing technology at an epistemological level he can open the "black box" of technological development that many economists and historians posit. However, in attacking the black-boxing of technological change by portraying it as knowledge change, Parayil simultaneously black boxes the socio-political determinants of knowledge content. He acknowledges their existence, be they through corporate backing, government funding, etc., but due to the fact that Parayil insists that the ultimate determinant of successful adoption of new technology is the selective-retention process of the recipient/producer dialectic, he feels that they are not enough to determine the shape and nature of new technology. They can give it a trajectory but no more (Parayil 1991a, 298).

Shiva, on the other hand, argues that the socio-political forces are far more significant than this. To understand the interests of those social groups who can mobilise technological production is to understand the ultimate nature of the technology (Shiva 1991, 21). Thus, she dismisses Parayil's claim that the recipient/producer dialectic is responsible for the nature and success of technology. For Shiva technological knowledge, both at the level of theoretical and artefactual content, embodies the intentions of those who brought it about. In the case of the Green Revolution the new technology was used as a "technological fix" to instantiate a new system of social relations. As we have seen, Parayil's account of the Green Revolution ignores the political context 
in which HYV originated due to his belief in the value-neutrality of technological knowledge. Thus, he sees nothing problematic in the transfer of Western technology into India. Technological knowledge being valueneutral, the analysis of the process of technological change should only begin at the point at which the technology began to evolve within India. The intentions behind the technological transfer are of no significance as the technology's evolution starts afresh. Thus, for Parayil, a "technological fix" is nothing more than the use of some technological improvement to solve a problem with technological knowledge.

Parayil's model of technological change also fails to capture what is significant in evaluating the consequences of the adoption of new technology. Parayil implicitly forwards the notion that technology is a prerequisite to development, and that movement towards a capitalist economic model constitutes progress. However, rather than believing that technology is immediately progressive simply by virtue of its physical presence (the black box theory Parayil rejects), he privileges a democratising interactive model of technological development and acceptance, in which the users of the new agricultural technology are just as much the arbiters of its success as the producers. However, even if such an interactive process takes place, it by no means guarantees the egalitarian process of technological development that Parayil assumes. By taking value-neutrality as a given of technological knowledge, Parayil turns a blind eye to the political dimensions of the wider technological nexus in which HYV technology is embedded. He thus ignores the fact that even if the peasant farmers of India were taught a simplified knowledge of the HYV technology before choosing to accept it, it does not follow that they understood the intentions that lay behind its development and transferral. Nor does it follow that they understood the commercial power relations into which they were entering. More significantly still, Parayil's knowledge bias results in him deeming a technological change a "success" solely on the grounds of whether the new knowledge was accepted and utilised by the peasantry. Having concluded on epistemic grounds that the change was a success, he then points to the increase in national grain yield that followed the adoption of the HYV technology, and reasons backwards that it must be solely due to the change in technological knowledge. In other words, having satisfied his epistemological criteria, he then moves to a material evaluation. Thus, by privileging technology as knowledge over technology as artefact or technique, Parayil overlooks the social and cultural effects that the change in technological practice brought about in the process of increasing grain yields. ${ }^{6}$ And by doing so he

\footnotetext{
${ }^{6}$ Parayil seems to view the peasant farmers as being a relatively homogenous group, representative of "Indian culture" in general. No ethnic, religious or caste distinctions among peasant farmers are considered.
} 
ignores the political and ecological dimensions of the Green Revolution's epistemic "success."

By endorsing the fact/value distinction and characterising technology as a form of knowledge, Parayil performs a double concealment of technology's inherently political nature. Placing technology in the realm of fact renders it value-neutral. It reifies technology into a natural object and disguises the social forces that determined its form and function. And construing technology as essentially epistemological then etherealises that which has been reified. The fact/value distinction congeals technology into a neutral object, and Parayil's epistemological characterisation abstracts that object into an idea.

This section has indicated the extent to which Shiva and Parayil's accounts of the Green Revolution are underpinned by their commitments to specific theoretical models of the character of modern technology and science. Whilst I do not wish to adjudicate the accuracy or otherwise of their respective Green Revolution histories, I will make a few comments on the adequacy of their theoretical models for the historical episode to which they are being applied. I suggest that Shiva's method of analysis, whether or not one agrees with her views on science and technology or her metaphysical pluralism, has a marked advantage over that of Parayil. By focusing on politico-economic interests at the point of technological origin, and socio-political and ecological consequences at the point of technological application, Shiva captures more of the significant dimensions of technology usage in the Green Revolution. Lacking Parayil's commitment to the primacy of technology as knowledge in evaluating technological change, she is able to grasp the purpose and effects of the epistemic dimension of the HYV technology as well as the effects of the artefactual and technical dimension. ${ }^{7}$ Whilst Parayil's instrumentalism rationalises away the political content of technological development and application by decontextualising technology, Shiva's mode of analysis rejects the fact/value distinction, recognising that the presupposition that such a distinction can even be made with regards to technology is itself a political decision. By assuming the inherently political character of technology Shiva's analysis seeks the political dimensions of the Green Revolution technology at all points of the historical narrative, from the context of its development to the consequences of its application. This enables her to draw explanatory links between the politics surrounding the genesis of the technology and the socio-political ramifications of its employment. Whereas Parayil's account decontextualises Green Revolution technology, Shiva's recontextualises it. And in so doing she exposes its political character

\footnotetext{
${ }^{7}$ This does not mean that Shiva's analysis is beyond criticism. One might, for instance, question the centrality of the role she accords Western political interests in the development of Green Revolution technology, given the concurrent development of similar technology under the decidedly non-capitalist and non-Western political system of Chinese communism (Patel 2013; Schmalzer 2016; Kilby 2019).
} 
and problematises the use of the Green Revolution as an exemplar for technological interventions in development contexts.

\section{Conclusion}

This paper has argued that the accounts given by Parayil and Shiva of the Green Revolution are underpinned and driven by theoretical commitments to certain models of technology and science, instrumentalist and determinist, respectively. Shiva's model stresses the political dimensions of technology, both at the level of development and application, and the material and epistemic consequences of technology transfer. Parayil, on the other hand, characterises technology as a form of knowledge and emphasises its instrumental, voluntaristic, and problem-solving features. I have suggested that the type of narrative that Shiva and Parayil provide of the history of the Green Revolution in India, and their ultimate judgement of its success or failure, is largely a reflection of these commitments.

Analysis of these Green Revolution narratives also draws attention to the ways in which the, often undeclared, commitment to a theory of technology determines the scope of analysis, and the determination of relevant factors within that analysis, in the evaluation of technology transfers. Shiva's determinist analysis understands technology as inherently political, and thereby as involving economic, gender and ecological factors. By viewing science and technology as imbued with the values and interests of the ruling interests a particular class/gender/culture, etc. Shiva's analysis focuses on the ideological and metaphysical dimensions of the technology transferred, its operating assumptions, the model of nature it instantiates, its epistemological norms, its cognitive hierarchies, etc. and the interests that they serve as intrinsic features of the technology itself. Any assessment of the efficacy or success of a technology transfer necessarily involves considerations of the effects of that technology. However when "technology" is understood in the expanded sense of Shiva's determinism, as artefact, knowledge, activity, metaphysics, and values, then the assessment must include all these elements as essential factors in forming an evaluative perspective. Parayil's analysis, on the other, takes it as given that technology is value-neutral. Consequently, the socioeconomic context of the technology's development is of no importance. The technology, understood on this account as essentially a form of knowledge, is outside the sphere of the political, and its success or failure can be assessed primarily by the diffusion of that knowledge and its application, and ultimately with reference to the abstract calculus of units produced per hectare.

In closing, I suggest that the analysis given here of the role played by technological theory in shaping historical narratives of the Green Revolution is not merely of historiographical relevance. The conceptual frameworks 
provided by theories of technology are employed both to analyse past episodes in the history of development, and to construct and evaluate future development projects. Though the positions taken by Shiva and Parayil might seem extreme, they represent instances of theoretical traditions that are still operative and influential. Shiva's technological determinism represents the minority view in technological analysis but her broad, socio-political model of technology continues to inform contemporary critiques of GMOs, water use, indigenous rights, and the commodification of nature. Parayil's instrumentalism is a version of the epistemology-focused social constructivism that appears to be the default position of many involved in development analysis ${ }^{8}$ and technology studies. ${ }^{9}$ I suggest that it is imperative that the technological models present in development narratives, past and future, be identified and critical scrutinised, for both have clear normative political implications.

This paper has analysed two development narratives regarding the same technological event and argued that, due to the competing technological theories that underlie these narratives, the two narratives produce very different assessments of the Green Revolution's efficacy. Whilst it would be wrong to extrapolate from this single technological instance to an account of the nature of technology that applied to all forms of technology (as Shiva appears to do on occasion) or even the use of the same technology in different historical or geopolitical contexts, it would be equally mistaken to assume that the Green Revolution is sui generis from a technological perspective. Rather than generalise from Shiva's specific account of the nature and function of Green Revolution technology to an account of technology in general, I suggest instead that her account provides certain conclusions that pertain to the nature and function of technological narratives in general.

Firstly, technological analyses are underpinned by theoretical stances on the nature of technology, either in general or with regards to specific technologies, and those stances have political implications. This being the case, these stances must be identified and examined as a necessary precondition to the acceptance of any technological narrative. Secondly, there is no apolitical or value-neutral technology. Technological narratives that suggest otherwise, typically by maintaining the fact/value distinction, are themselves promoting a political narrative. By portraying technology as value-neutral, these narratives shield the political dimensions of the construction/selection/application of technology from sight and in so doing serve the political function of normalising such an outlook, and thereby endorsing the status quo. Thirdly, technological narratives should as a matter of course meet the criteria

\footnotetext{
${ }^{8}$ See for instance Evenson (2005) or Evenson and Gollin (2003).

${ }^{9}$ Since the so-called empirical turn in the 1990s, technology studies have prioritised descriptivism over critique. See Du Toit and Swer (2020).
} 
exemplified in Shiva's analysis of the Green Revolution. Namely, that they should provide a descriptive account of the specific social and political context that brought about the development and application of the technology under study, including the possible paths of technological development that were not taken; that they should be normative in that they offer an emancipatory norms from which the situation under study may be critiqued, as opposed to simply describing the situation as it is; and that they should identify viable possibilities that transcend the situation under analysis, and thereby create transformative praxis.

I suggest that it is only if we apply such criteria to technologically-driven development that we can envision a form of development that places technological control in the hands of those that development seeks to empower. For, as the comparison of Shiva and Parayil indicated, a process of development that uncritically accepts that notion of the value-neutrality of technology is one that will efface the concrete materialities of the environment affected: the ecological, the social and the psychological. And only a process that subjects the technological presumptions behind development paradigms to political critique can deliver development that does not enable the exploitation of the environment, the exacerbation of social and gender divisions, and the concentration of technological power in the hands of an economic minority. Only a technology that is transparent to its users in its design, operations and enabling conditions, can truly empower. And a technology that is opaque in some or all of these regards can just as easily enchain as liberate.

\section{Disclosure Statement}

No potential conflict of interest was reported by the author(s).

\section{References}

Bridgstock, M. 1998. "The Scientific Community." In Science, Technology and Society, edited by M. Bridgstock, 15-39. Cambridge: Cambridge University Press. Byres, T., B. Crow, and M.-W. Ho. 1983. The Green Revolution in India. Milton Keynes: Open University Press.

Du Toit, J., and G. Swer. 2020. “A Manifesto for Messy Philosophy of Technology: The Past and Future of an Academic Field." Theory of Science 42 (2): 231-252. doi:10.46938/tv.2020.491.

Evenson, R. E. 2005. "Besting Malthus: The Green Revolution.” Proceedings of the American Philosophical Society 149 (4): 469-486.

Evenson, R. E., and D. Gollin. 2003. "Assessing the Impact of the Green Revolution, 1960 to 2000." Science 300 (5620): 758-762.

Kilby, P. 2019. The Green Revolution: Narrative of Politics, Technology and Gender. London: Routledge.

Marcuse, H. 1964. One-Dimensional Man. London: Routledge. 
McCarthy, D. R. 2017. "Introduction: Technology in World Politics." In Technology and World Politics: An Introduction, edited by D. R. McCarthy, 1-21. London: Routledge.

Mitcham, C. 1994. Thinking Through Technology. London: University of Chicago Press.

Mumford, L. 1934. Technics and Civilization. London: Routledge \& Kegan Paul.

Mumford, L. 1967. The Myth of the Machine. New York: Harcourt Brace Jovanovich.

Parayil, G. 1991a. "Technological Knowledge and Technological Change." Technology in Society 13 (3): 289-304.

Parayil, G. 1991b. "Technology as Knowledge: An Empirical Affirmation." Knowledge: Creation, Diffusion, Utilization 13 (1): 36-48.

Parayil, G. 1991c. "Technological Change as a Problem-Solving Activity." Technological Forecasting and Social Change 40 (3): 235-247.

Parayil, G. 1992. "The Green Revolution in India: A Case Study of Technological Change." Technology and Culture 33 (4): 737-756.

Parayil, G. 1997. "Practical Reflexivity as a Heuristic for Theorising Technological Change.” Technology in Society 19 (2): 161-175.

Patel, R. 2013. “The Long Green Revolution.” The Journal of Peasant Studies 40 (1): $1-63$.

Reinfelder, M. 1980. “Introduction: Breaking the Spell of Technicism.” In Outlines of a Critique of Technology, edited by P. Slater, 9-37. London: Ink Links.

Schmalzer, S. 2016. Red Revolution, Green Revolution. Chicago, IL: University of Chicago Press.

Shiva, V. 1988. "Reductionist Science as Epistemological Violence." In Science, Hegemony and Violence, edited by A. Nandy, 232-256. Oxford: United Nations University.

Shiva, V. 1989. Staying Alive. London: Zed Books.

Shiva, V. 1991. The Violence of the Green Revolution. London: Zed Books.

Shiva, V. 1993. "The Seed and the Earth: Biotechnology and the Colonisation of Regeneration.” In Minding our Lives, edited by V. Shiva, 129-143. New Delhi: Kali for Women.

Swer, G. 2014. "Determining Technology: Myopia and Dystopia." South African Journal of Philosophy 33 (2): 201-210.

Swer, G. 2019. "Seeds of Violence: Ecofeminism, Technology, and Ecofeminist Philosophy of Technology." In Feminist Philosophy of Technology, edited by J. Loh and M. Coeckelbergh, 247-264. Stuttgart: J.B. Metzler.

Swer, G. 2020. "Nature, Gender and Technology: The Ontological Foundations of Shiva's Ecofeminist Philosophy." Comparative and Continental Philosophy 12 (2): $118-131$.

Tiles, M., and H. Oberdiek. 1995. Living in a Technological Culture. London: Routledge. 